\title{
Impact of lubrication on the tribological behaviour of PTFE composites for guide rings application
}

\author{
M TRABELSI ${ }^{1}$, M KHARRAT ${ }^{1,2, *}$ and M DAMMAK ${ }^{1,2}$ \\ ${ }^{1}$ Laboratory of Electromechanical Systems, National Engineering School of Sfax, P.O. Box 1173, 3038 Sfax, Tunisia \\ ${ }^{2}$ Preparatory Institute for Engineering Studies of Sfax, P.O. Box 1172, 3018 Sfax, Tunisia
}

MS received 7 May 2015; accepted 16 March 2016

\begin{abstract}
In this study, the friction and wear behaviours of polytetrafluoroethylene (PTFE)-based composites were comparatively evaluated under dry sliding and oil-lubricated conditions. Two PTFE composites filled with bronze and bronze + molybdenum disulfide $\left(\mathrm{MoS}_{2}\right)$ were considered. These composites were used as guide rings for hydraulic actuating cylinder. Friction and wear tests of the composite specimens sliding against high chromium steel ball were conducted using reciprocating linear tribometer. The wear mechanisms of the composites under the two different sliding conditions were analysed and discussed based on scanning electron microscopic (SEM) examinations of the worn surface and optical micrographs of the steel counterface. Under the oil-lubricated condition, the friction and wear behaviours of the composites were considerably improved if compared to that under the dry sliding. The oil adsorbed layer limited the transfer of the composite to the steel counterface and avoided the oxidation of the $\mathrm{MoS}_{2}$ during the sliding test.
\end{abstract}

Keywords. PTFE; composite; bronze; $\mathrm{MoS}_{2}$; friction; wear; oil-lubrication; dry sliding.

\section{Introduction}

Polytetrafluoroethylene (PTFE) composites were widely used as engineering materials due to their good mechanical and tribological properties. These properties were dependent on the types and the content level of fillers [1-3]. Among them, bronze powder was used as filler in the PTFE matrix and its effects on the friction and wear behaviour of the PTFE composites were studied by many researchers $[4,5]$. Besides, the addition of high percentage of bronze powder to PTFE, results in a composite having high thermal conductivity and better wear resistance than most other compounds [4]. Sure enough, Bahadur and Tabor [6] and Blanchet and Kennedy [7] have concluded that the fillers interrupted the destruction of PTFE banded structure and formation of large debris during the friction process. Moreover, the wear mechanisms of the PTFE composites were characterized by the formation of a PTFE transfer film on the counter surface and the adhesion of this transfer film was improved by the content level of the bronze filler [8]. However, the fillers can lead to the increase of the friction coefficient, activate abrasion and reduce the mechanic integrity and chemical resistance of the composite during sliding [9].

To preserve the best friction behaviour of the PTFE, solid lubricant such as molybdenum disulfide $\left(\mathrm{MoS}_{2}\right)$ was added with the hard fillers. But this hypothesis is not necessarily true, and the fillers with solid lubrication together, may not enhance the performance of the composite at all the

\footnotetext{
*Author for correspondence (mohamed.kharrat@ipeis.rnu.tn)
}

operating conditions [10]. Also, the interaction of the fillers with the polymeric matrix is sensitive to the wearing situations and the operating conditions [11]. Presumably, wear of the composites should be studied at different working conditions.

The friction and wear behaviours of the PTFE filled with bronze or $\mathrm{MoS}_{2}$ under dry sliding condition have been studied by many researches $[4,12,13]$. However, the field application of these composites was enlarged and PTFE-based composites have been used in fluid environments. According to the many scientific researchers, the friction and wear of the PTFE composites have significantly been reduced in the lubricated condition [14-17]. Moreover, the authors found that in the lubricated condition, the PTFE-based composites had a different tribological behaviour than the pure PTFE material, when the pressure and temperature varied $[18,19]$. Yet, there is a dearth of information about the friction and wear behaviour of the bronze $+\mathrm{MoS}_{2}$ filled PTFE under the oil lubricated condition.

In this paper, the attempt was made to evaluate the tribological behaviour of the PTFE-based composites filled with $\mathrm{MoS}_{2}$ and/or bronze particles under the lubricated condition using a reciprocating linear tribometer. The pick of the latter sliding condition is due to the fact that these composite materials could be set on the piston of the hydraulic actuating cylinder. Moreover, the evolutions of the friction coefficient, the wear rate and wear process, for each of the considered composites with respect to the number of sliding cycles were analysed and compared with those under the dry sliding. This is because the studied composites could also be set on the rod of the hydraulic actuating cylinder. 
Table 1. PTFE-based composite materials.

\begin{tabular}{|c|c|c|c|c|}
\hline Appointment of composites & PTFE (wt $\%)$ & Bronze (wt \%) & $\mathrm{MoS}_{2}(\mathrm{wt} \%)$ & Characteristics of fillers \\
\hline Composite A & 55 & 40 & $\sim 5$ & Bronze $10-30 \mu \mathrm{m}$ size \\
\hline Composite B & 70 & 30 & 0 & Bronze $10-30 \mu \mathrm{m}$ size \\
\hline
\end{tabular}

Table 2. Mechanical properties of the PTFE-based composites.

\begin{tabular}{lccc}
\hline & $\begin{array}{c}\text { Young modulus } \\
(\mathrm{MPa})\end{array}$ & $\begin{array}{c}\text { Ultimate stress } \\
(\mathrm{MPa})\end{array}$ & $\begin{array}{c}\text { Ultimate strain } \\
(\%)\end{array}$ \\
\hline Composite A & $582 \pm 2$ & $16.5 \pm 0.2$ & $512 \pm 7$ \\
Composite B & $676 \pm 4$ & $23.5 \pm 0.6$ & $521 \pm 8$ \\
\hline
\end{tabular}

Table 3. Characteristics of the used lubricant.

\begin{tabular}{ll}
\hline Density at $15^{\circ} \mathrm{C}$ & $0.87 \mathrm{~kg} \mathrm{l}^{-1}$ \\
Viscosity at $40^{\circ} \mathrm{C}$ & $31.2 \mathrm{~mm}^{2} \mathrm{~s}^{-1}$ \\
Viscosity index & 100 \\
Flash point & $202^{\circ} \mathrm{C}$ \\
\hline
\end{tabular}

\section{Experimental}

\subsection{Materials}

Two commercially available PTFE composite materials used as guide rings for hydraulic actuating cylinder were considered in this study. These materials were proprietary products supplied by Dichtomatik. They were supplied as strips with a section of $25 \times 3 \mathrm{~mm}^{2}$. The filler particles added to the PTFE matrix were bronze and bronze $+\mathrm{MoS}_{2}$. For each composite material, the weight fractions of the constituents were identified using fire loss technique followed by atomic absorption analyses [20]. The mechanical properties of the PTFE composites were determined under tensile loading [20]. The chemical composition and the mechanical properties of these materials are listed in tables 1 and 2, respectively.

In all friction tests, the specimens were cut from the supplied strips with $20 \times 25 \times 3 \mathrm{~mm}^{3}$ dimensions. The counterface was high chromium steel ball $(100 \mathrm{Cr} 6)$ with a surface roughness of $0.06 \mu \mathrm{m}$ and a radius of $19 \mathrm{~mm}$. For all the tests, the lubricant used was commercially available synthetic oil. This lubricant is a high performance anti-wear hydraulic oil designed in the Gulf harmony series by AW 32. It is compatible with sealing materials and multi-metals commonly used in the hydraulic actuating cylinder. The characteristics of the lubricant were listed in table 3 .

\subsection{Microstructure analysis}

The microstructures of specimens were examined using the JSM-5400 model scanning electron microscope (SEM). The micrographs of each specimen are presented in figure 1. For the two composites, the homogeneous distribution of the filler particles in the PTFE matrix can be clearly seen. But, no good wetting of the bronze particles with the matrix was observed for both the composites (figure $1 \mathrm{a}^{\prime}$ and $\mathrm{b}^{\prime}$ ). Since there are no strong bonds between the fillers and the matrix in the composites, these interfaces become the places of crack initiation. This has a harmful effect on their mechanical properties. In fact, it can be seen from table 2 that the composite A has lower ultimate stress than the composite B (16.5 and 23.5 MPa, respectively). This is because the former contains the highest wt $\%$ of fillers.

\subsection{Friction and wear test}

The friction and wear characterizations of the considered PTFE composites were performed using a reciprocating ball-on-flat tribometer under lubricated condition (figure 2). The tribometer allows the contact between the steel ball and the composite specimen under a constant normal load. The specimen was glued on the bottom of the oil bath and then, it was totally covered by oil before the start of the test. Regarding the wear test arrangement, it consists in keeping stationary the steel ball and a tangential cyclic motion was applied to the specimen, by means of a crank system driven by an electric motor, which was controlled by an electronic speed regulator. The tangential displacement amplitude and frequency were adjusted for the first time. The tangential load was measured by a load cell located between the specimen holder and the slider of the crank system. The output of this load cell was continuously stored by using a data acquisition system. Before each test, the steel ball and the composite sample surfaces were thoroughly cleaned with ethanol and then dried. The friction and wear test conditions selected for our study are given in table 4 . The same ball-on-flat tribometer was used to characterize the friction and wear behaviours of both composites A and B, under the dry condition for the sake of comparison. For each PTFE composite, a minimum of three tests were performed for a given test duration. The surface morphologies of the wear tracks on the PTFE composite and the steel counterface were examined using both SEM and optical microscope (OM).

After each wear test, SJ-210 hand-held roughness tester was used to establish surface profile in the transverse direction across the wear scar on the PTFE composite specimen. On the basis of this profile, the cross section, $S\left(\mathrm{~mm}^{2}\right)$ of the wear groove was calculated. The volume loss, $V\left(\mathrm{~mm}^{3}\right)$ of the composite specimen due to the wear was calculated as:

$$
V=S \times d,
$$



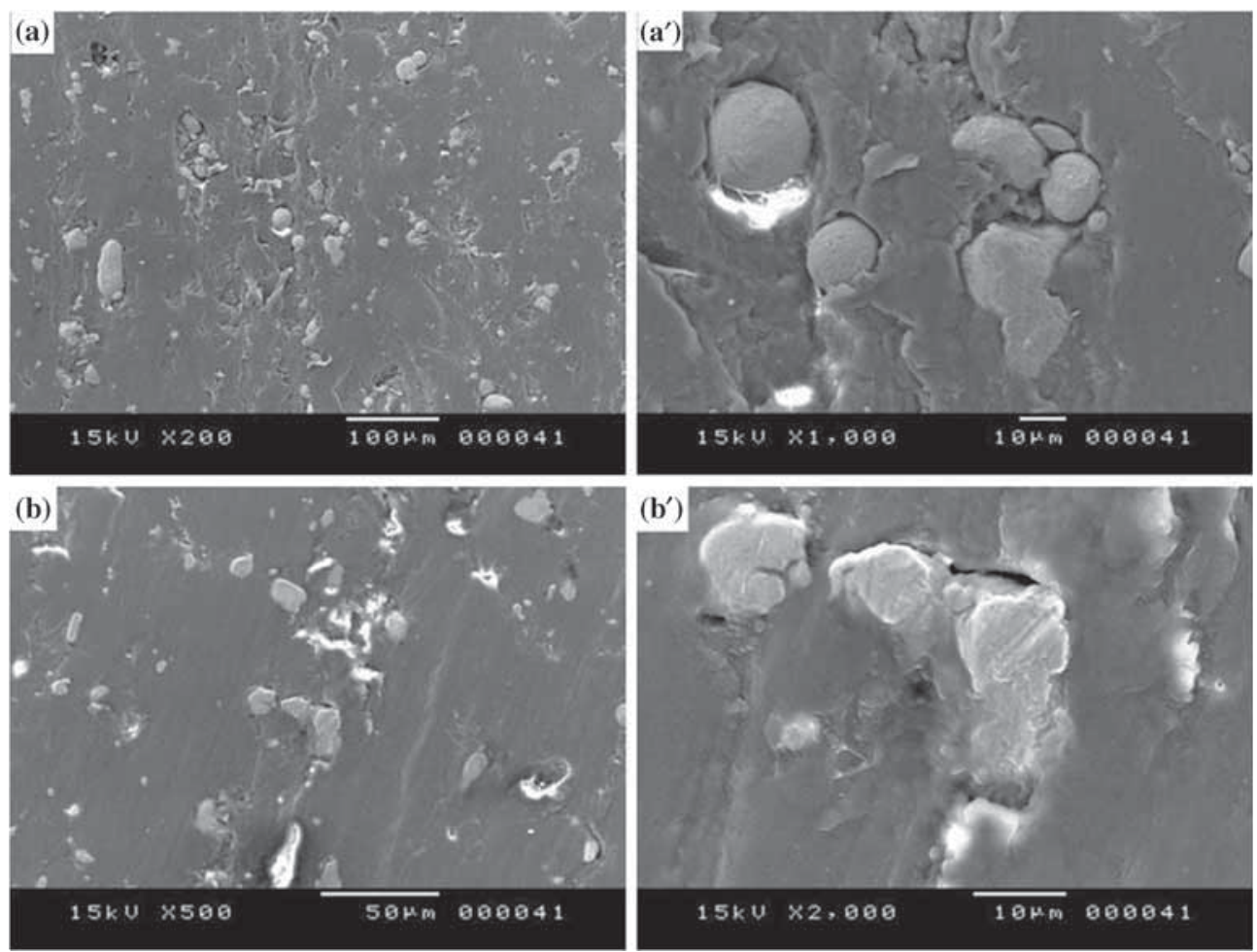

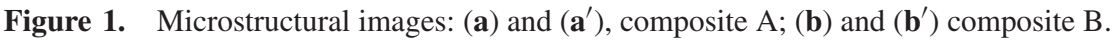

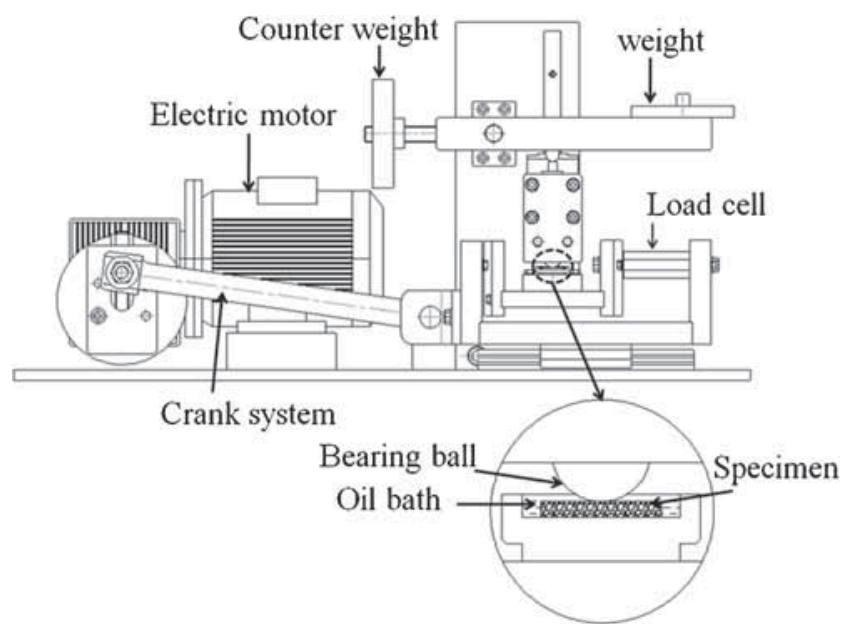

Figure 2. Reciprocating ball-on-flat tribometer.

Table 4. Friction and wear test conditions.

\begin{tabular}{ll}
\hline Parameters & Experimental conditions \\
\hline Normal load $(\mathrm{N})$ & 81.3 \\
Displacement amplitude $(\mathrm{mm})$ & \pm 7.5 \\
Frequency $(\mathrm{Hz})$ & 1 \\
Temperature $\left({ }^{\circ} \mathrm{C}\right)$ & $20-25$ \\
Humidity $(\%)$ & $50-60$ \\
Number of cycles & 7,$200 ; 18,000 ; 25,200 ; 36,000 ; 79,200$ \\
Surface roughness, $R_{\mathrm{a}}(\mu \mathrm{m})$ & Composite A: $16 ;$ Composite B: 2.3 \\
\hline
\end{tabular}

where $d=15 \mathrm{~mm}$ is the length of the sliding stroke. The specific wear rate, $K\left(\mathrm{~mm}^{3} \mathrm{~N}^{-1} \mathrm{~m}^{-1}\right)$ was calculated using the following expression [21]:

$$
K=\frac{V}{\left(F_{\mathrm{n}} \times L\right)}
$$

where $V$ is the volume loss $\left(\mathrm{mm}^{3}\right), F_{\mathrm{n}}$ the normal load $(\mathrm{N})$ and $L$ the sliding distance $(\mathrm{m})$.

\section{Results and discussion}

Figure 3 shows the typical evolutions of the friction coefficient with the number of cycles for the considered PTFE composites under dry sliding and lubricated conditions. It can be clearly seen that the friction behaviour of the composites was improved by lubrication. In effect, for the composite A, friction coefficient reaches a value of 0.07 after 36,000 cycles under the lubricated condition, while under the dry sliding, it reaches a value of 0.26 after the same number of cycles. Meanwhile, the friction coefficient of the composite $B$ reaches a value of 0.06 under the lubricated condition and it reaches a value of 0.21 under the dry sliding. So, the friction coefficients of the composites decreased significantly by oil lubrication. Moreover, under the lubricated condition, the friction coefficient of the composites A and B experiences a progressive increase and reaches a constant value at the end of the test. This indicates that an equilibrium stage was achieved for the composites after 79,200 cycles. While, 


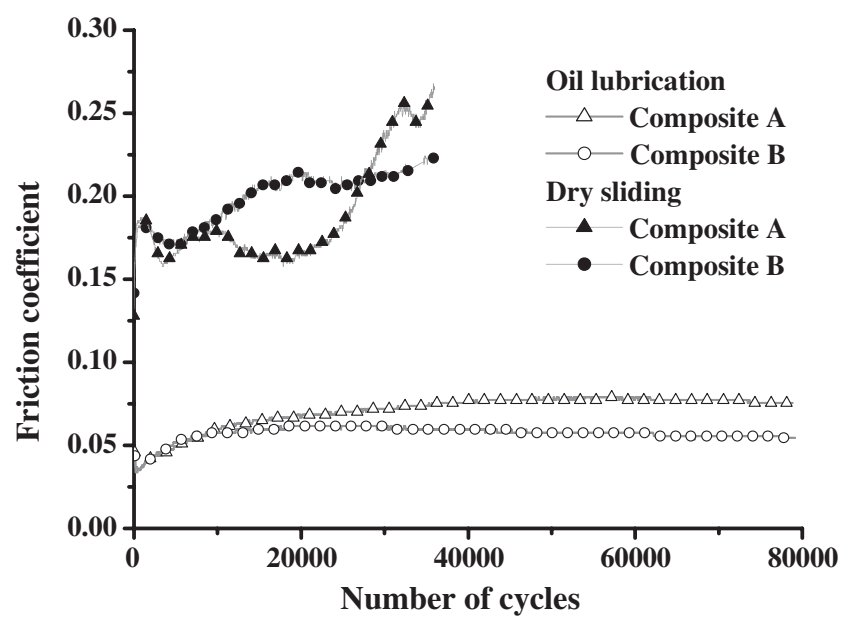

Figure 3. Evolution of the friction coefficient with the number of cycles for the two PTFE composites.

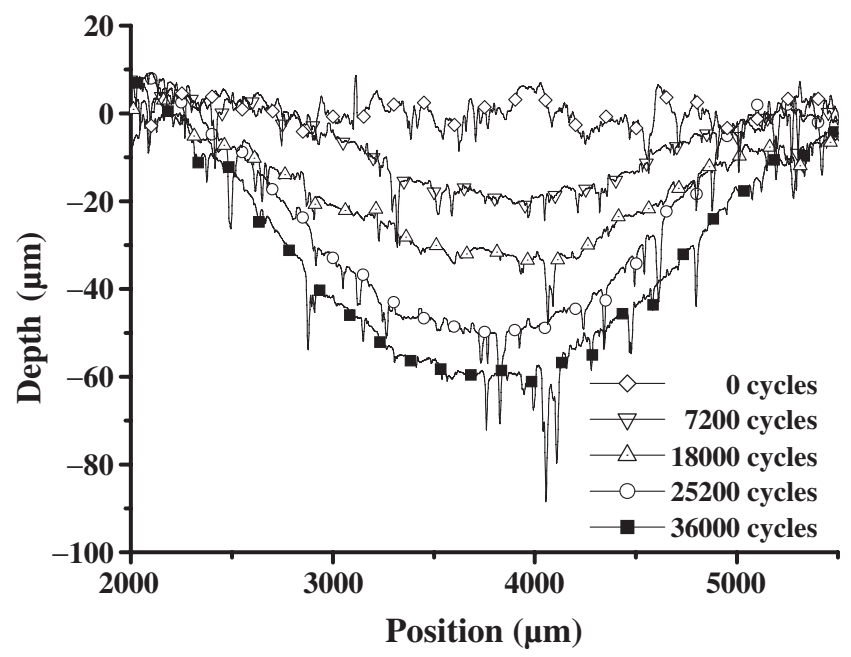

Figure 4. Typical profiles of the wear groove of the composite B.

under the dry sliding, the friction coefficient of the composite A experiences a sharp increase near the end of the test. As for the composite B, its friction coefficient tends to stabilize around a constant value after 36,000 cycles.

For each of the composites, the volume loss, $V\left(\mathrm{~mm}^{3}\right)$ was calculated from the established surface profile. As an example, typical profiles of the wear groove on the surface of composite B were presented in figure 4. Evolution of the wear loss, represented by the volume loss with the number of cycles is illustrated in figure 5 for the composites $\mathrm{A}$ and B under dry- and oil-lubricated sliding conditions. Also, so as to compare the progress of the wear severity of the composites under the latter conditions, the specific wear rate, $K$ $\left(\mathrm{mm}^{3} \mathrm{~N}^{-1} \mathrm{~m}^{-1}\right)$ is plotted against the number of cycles in figure 6 .

It is seen from figure 5 that the wear loss of the composites A and B decreases significantly under the lubricated condition compared with the dry sliding condition. Moreover,

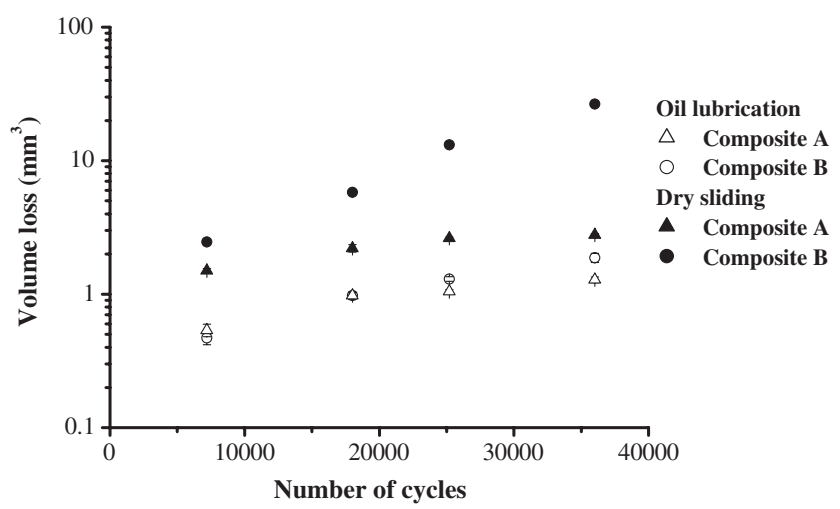

Figure 5. Evolution of the volume loss of the composites with the number of cycles.

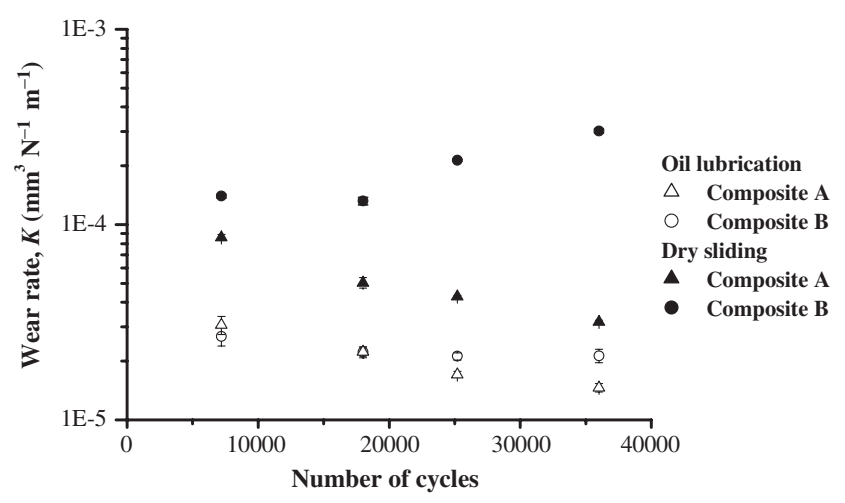

Figure 6. Evolution of the wear rate with the number of cycles for different PTFE composites.

under both dry- and oil-lubricated conditions, the wear loss of the composite A has a tendency to stabilize when the number of cycles increases. Meanwhile, the wear loss of the composite $\mathrm{B}$ increases progressively. Also at all conditions, the wear of composite A keeps the lowest value.

Figure 6 shows that the specific wear rate of composite A decreased gradually under both lubricated and dry conditions. As for the composite B, the wear rate remained stable under the oil lubricated condition, but under the dry sliding, it increases from a certain number of cycles. Moreover, after the test duration of 36,000 cycles, the wear rate of composite $B$ was $14 \times$ reduced by the adsorbed oil layer on the surface of the specimen, while for the composite A, it was only $2 \times$ reduced.

Figure 7 shows the SEM micrographs of the worn surface of the composite A and the OM observations of the steel counterface under dry- and oil-lubricated sliding conditions. It was found that after 36,000 cycles of sliding under the oillubricated condition, the worn surface of the composite and the steel counterface were characterized by smooth surfaces and the presence of debris on both wear tracks of the composite and the steel ball (figure 7a and c). Contrary to the above, a running film with micro-cracks and presence of flakes was shown on the wear track of the composite under the dry sliding (figure $7 b$ ). While multiple grooves, in parallel with 

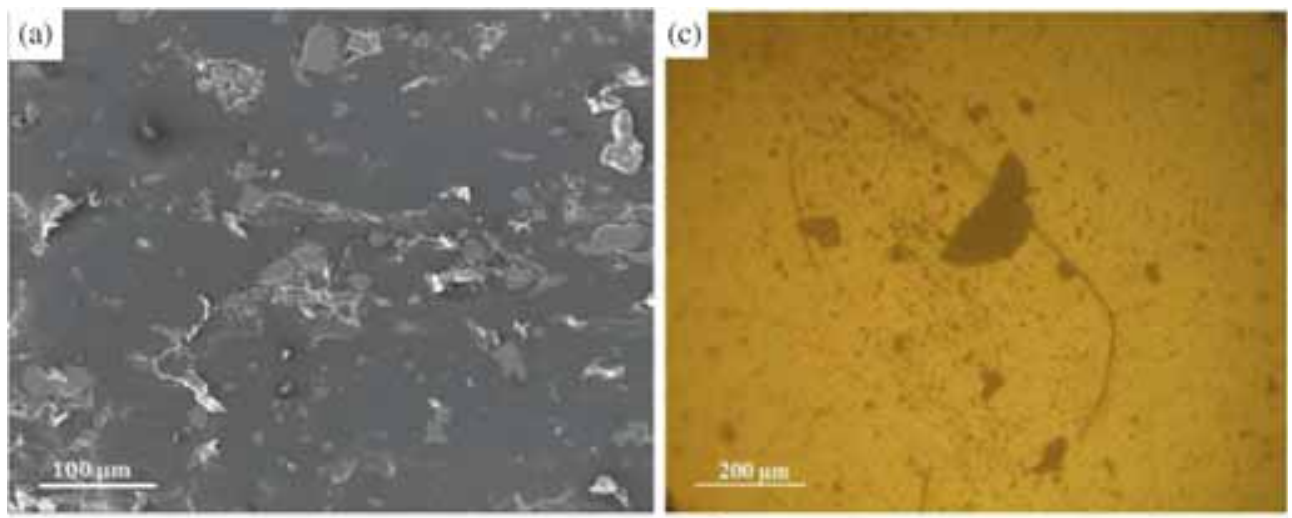

(b)

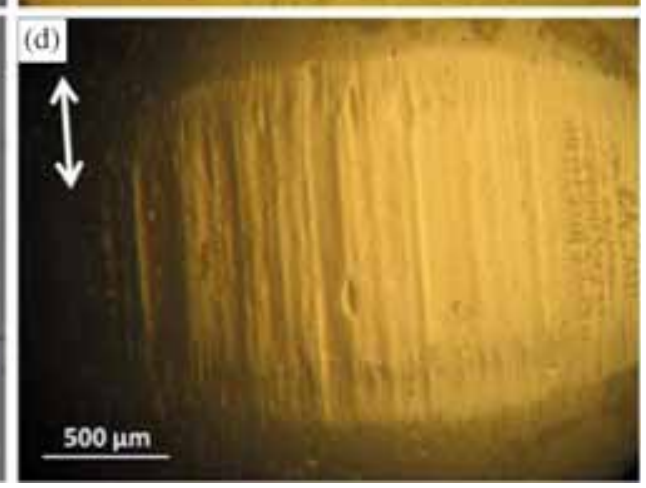

Figure 7. SEM micrographs of the worn surface of the composite A and optical micrographs of the steel counterface after 36,000 cycles: (a) composite and (c) steel, under oil lubrication; (b) composite and (d) steel, under dry sliding.
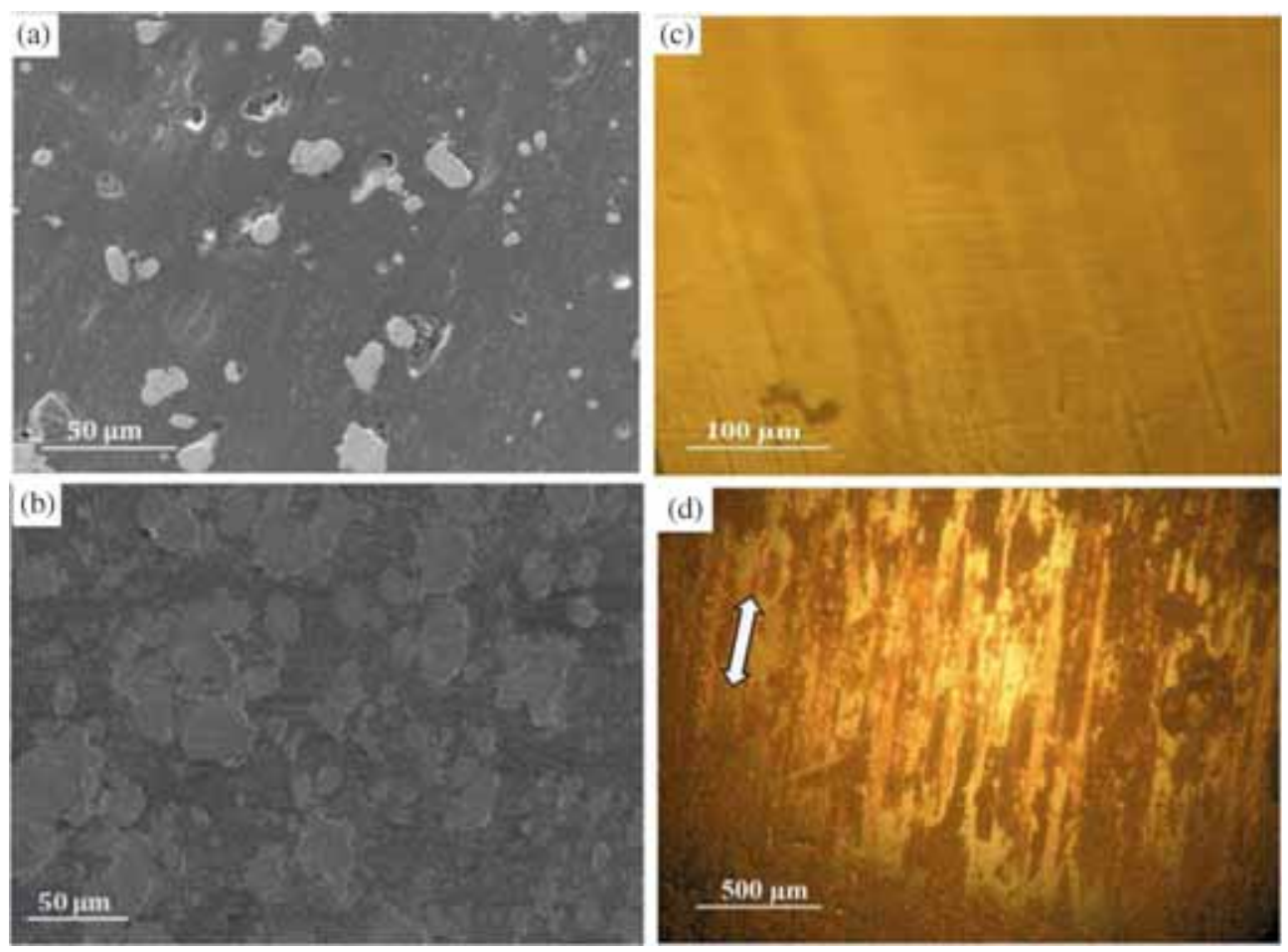

Figure 8. SEM micrographs of the worn surface of the composite B and optical micrographs of the steel counterface after 36,000 cycles: (a) composite and (c) steel, under oil lubrication; (b) composite and (d) steel, under dry sliding. 

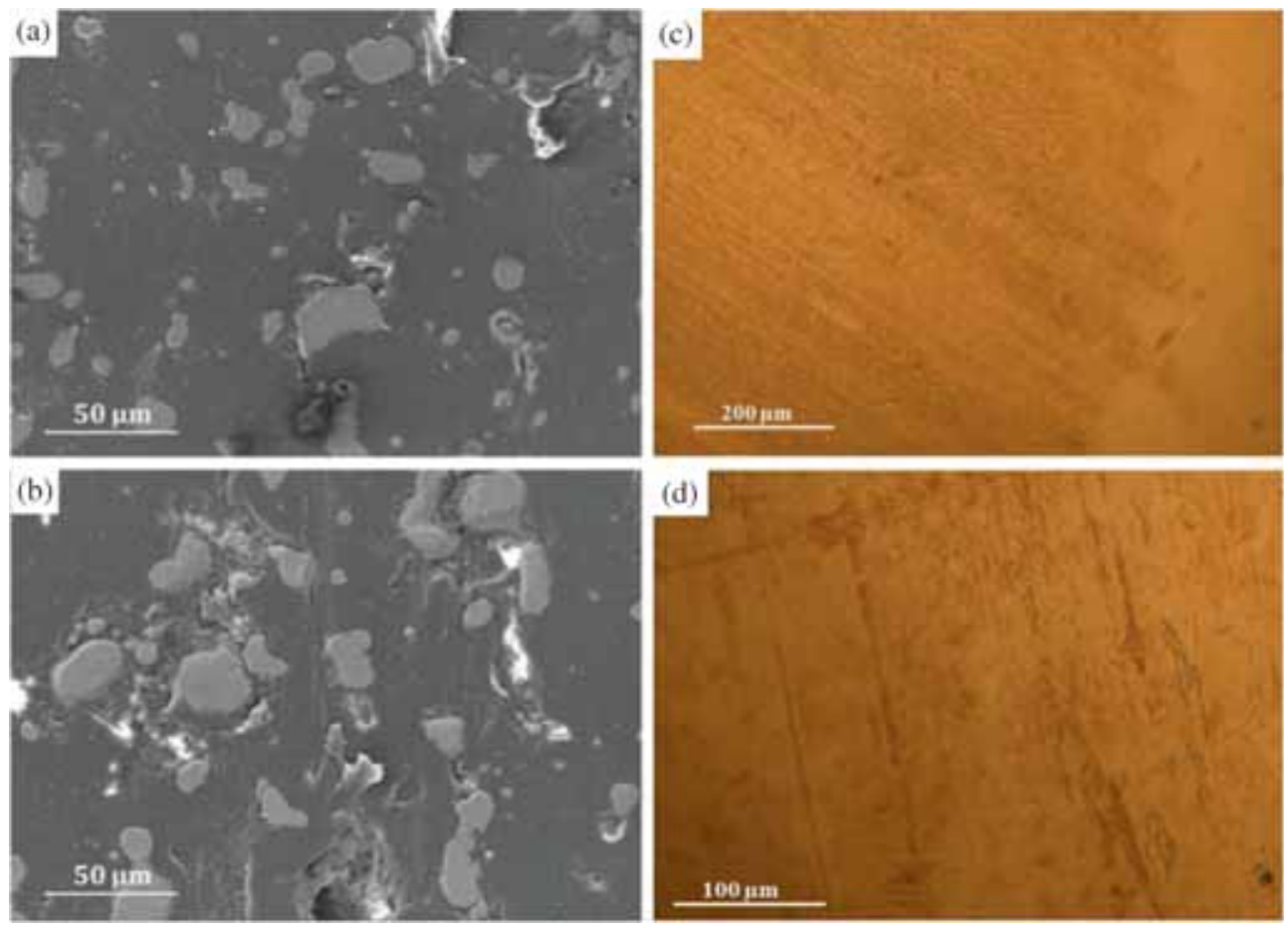

Figure 9. SEM micrographs of the worn surfaces of the composites and optical micrographs of the steel counterfaces after 79,200 cycles of sliding under oil lubrication: (a) composite B and (c) steel; (b) composite A and (d) steel.

the sliding direction, were observed on the steel counterface (figure 7d). The abrasive wear mechanism on the latter was due to the hard particles, which were produced during the dry sliding. In fact, authors found that during the wear process, the $\mathrm{MoS}_{2}$ became $\mathrm{MoO}_{3}$ under the effects of the both thermal and compressive or shear stresses $[22,23]$. However, under the lubricated condition, the lubrication and cooling effects of the oil film avoided the oxidation of the fillers, in particular, the chemical transformation of the $\mathrm{MoS}_{2}$ to $\mathrm{MoO}_{3}$, and inhibited the gross destruction of the PTFE, while the heat generated at the contact was abated. Consequently, friction and wear behaviours of the composite were improved under the lubricated condition.

Figure 8 shows the SEM micrographs of the worn surface of the composite $\mathrm{B}$ and the OM observations of the steel counterface under dry- and oil-lubricated sliding conditions. Also, it was found that after 36,000 cycles of sliding under oil lubrication, the worn surface of the composite and the steel counterface were characterized by smooth surfaces (figure 8a and c). While under the dry condition, the worn surface was characterized by the presence of 'third body' particles. These particles came from the destruction of the transfer film already observed on the steel counterface (figure 8d) by the hard wear debris. Thus, the oil lubrication limited the transfer of the composite on the steel counterface. Consequently, the wear of the composite decreased significantly. Moreover, for the same reasons previously quoted for the composite A, the friction behaviour of the composite B was improved.
Figure 9 shows the SEM micrographs of the worn surfaces of the composites and the OM observations of the steel counterfaces under the oil lubricated condition after 79,200 cycles. It was shown that the amount of the fillers at the surface of the wear track increased for composites A and B. Moreover, bronze particles underwent either a plastic deformation or wear under the shear and compressive stresses, while their shape was straight out flat (figure 9a and b). On the other hand, the presence of a slight transfer film on the steel counterface of the composite B was noticed, but the steel counterface of the composite A was smooth (figure 9c and d). So, the transfer of the composite was greatly reduced by lubrication, but it still occurred as it had been reported elsewhere [11]. This behaviour contributed to the decrease in the friction coefficient and the wear of the composite.

\section{Conclusions}

Tribological study was investigated on the composite A $\left(\mathrm{PTFE}+\right.$ bronze $\left.+\mathrm{MoS}_{2}\right)$ and the composite $\mathrm{B}(\mathrm{PTFE}+$ bronze) using a linear reciprocating tribometer under dry and lubricated conditions. A summary of the major findings is as follows:

(1) The friction coefficients of the composites under the lubricated condition were more than three times less than those under dry sliding. Moreover, under the dry condition, friction coefficient of the composite A undergoes a sharp increase after 20,000 cycles. It was seen 
that the friction behaviours of the composites was greatly improved by lubrication.

(2) The wear rate of the composite B was significantly improved by lubrication. It was reduced after the test duration of 36,000 cycles by more than one decade. As for the composite $\mathrm{A}$, the wear rate was just twice reduced for the same test duration. Thus, lubrication can play an appreciable reduction effect on the wear of the composite, when there is insufficient amount of fillers.

(3) PTFE composites are characterized by smooth worn surface under oil lubricated sliding and the gross destruction of the PTFE was greatly avoided by the cooling effect of the oil lubricant. While, under dry sliding, it was seen an abrasive wear on the steel counterface of the composite A and a thick transfer film on the steel counterface of the composite B.

(4) The transfer of the composite onto the steel counterface was greatly reduced by oil lubricated condition, but it still takes place in particular at the absence of the solid lubricant as the $\mathrm{MoS}_{2}$ which restrains the transferring of the PTFE to the steel counterface.

(5) The results of this tribological study showed the impact of oil lubrication on the durability of both composites $\mathrm{A}$ and $\mathrm{B}$ used as guide rings for hydraulic actuating cylinder.

\section{References}

[1] Khoddamzadeh A, Liu R and Wu X 2009 Wear 266646

[2] Li J and Sheng X H 2010 Mater. Technol. 2530
[3] Aderikha V N, Krasnov A P, Shapovalov V A and Golub A S 2014 Wear 320135

[4] Tevrüz T 1999 Wear 23061

[5] Unal H, Sen U and Mimaroglu A 2006 Mater. Des. 27694

[6] Bahadur S and Tabor D 1984 Wear 981

[7] Blanchet T A and Kennedy F E 1992 Wear 153229

[8] Wang Y and Yan F 2007 Wear 262876

[9] Briscoe B, Pogosian A and Tabor D 1974 Wear 2719

[10] Bijwe J, Rajesh J, Jeyakumar A, Ghosh A and Tewari U S 2000 Tribol. Int. 33697

[11] Jia J H, Zhou H D, Gao S Q and Chen J M 2003 Mater. Sci. Eng. 35648

[12] Tanaka K and Kawakami S 1982 Wear 79221

[13] Conte M, Pinedo B and Igartua A 2013 Wear 30781

[14] Kharde Y R and Saisrinadh K V 2011 Bull. Mater. Sci. 341003

[15] Qian-qian S and Xian-hua C 2006 Wear 2601243

[16] Li J 2009 Curr. Appl. Phys. 91445

[17] Golchin A, Simmons G F and Glavatskih S B 2012 Tribol. Int. 4854

[18] Akagaki T, Kawabata M and Kato K 2000 Proceedings of the International Tribology Conference, Nagasaki, Japan, p. 917

[19] Zhang Z Z, Xue Q J, Liu W M and Shen W C 1997 Wear 210151

[20] Trabelsi M, Kharrat M and Dammak M 2016 T. Indian I. Metals 691119

[21] G 99-05 Standard Test Method for wear testing with a pin-ondisk apparatus 2005 ASTM International, USA

[22] Zhang H J, Zhang Z Z and Guo F 2011 Tribol. T. 54417

[23] Li X, Gao Y, Xing J, Wang Y and Fang L 2004 Wear 257279 